\title{
Water migration in unsaturated partially hydrophobic soils
}

\section{Luisa Fernanda Orozco}

Department of Civil and Environmental Engineering, University of Los Andes, Bogotá, Colombia

\section{Bernardo Caicedo}

Department of Civil and Environmental Engineering, University of Los Andes, Bogotá, Colombia

\begin{abstract}
This article presents new insights into effects of hydrophobic particles on water migration in fine graded soils. The experimental setup for this study uses a column of soil instrumented with sensors that allows direct measurements of soil water content at different heights of the column during capillary rise, infiltration under imposed pressure and drainage. To precisely determine the proportion of hydrophobic particles the fine grained soil was mixed with microparticles of Teflon (PTFE). The water retention curve was measured for mixtures with three different percentages of hydrophobic particles: $0 \%, 2 \%$, and $5 \%$ by weight. In addition, the water repulsion curve of the PTFE particles was measured using a water intrusion test. This test showed high water repellency that modifies the unsaturated characteristics of the mixtures. Results of this study show a huge effect of hydrophobic particles on capillary rise, but water repellency decreases when pressure is imposed and becomes relevant again during the drainage process. This study provides a new survey that could be useful for understanding the benefits and limitations of soil treatments with hydrophobic chemical products.
\end{abstract}

Keywords: hydrophobic, capillary rise, unsaturated flow, water repellence.

\section{INTRODUCTION}

The hydrology of tropical regions, characterized by alternation of heavy rainy seasons with dry seasons, impacts roads and embankments. Hydrophobization of soils has been proposed to reduce the impact of heavy rains because materials with hydrophobic properties can resist or retard water infiltration (Brandt, 1969). Nevertheless, since fluctuation of hydric conditions in the field involves a combination of capillary rise, infiltration under pressure, and drying, an understanding of the mechanisms that modify water flows in partially hydrophobic soils is crucial for establishing the benefits of this treatment.

Soil hydrophobization is possible through modification of the contact angle between water and soil particles. This is usually achieved by applying a surfactant around the surface of soil particles (Fleureau et al., 1988, Liu et al., 2012, Diamantopoulos et al., 2013). Although some studies have shown that only small proportion of a hydrophobic product in a soil is necessary to reach high degrees of water repellency (Caicedo et al., 1988), artificial treatment with chemical products leads to uncertainty about the best proportion of hydrophobic-hydrophilic particles and about the interparticle water flow mechanics.

While it is possible to measure the contact angle between a water drop and a smooth surface, direct geometric measurements of soils are unlikely due to surface heterogeneity (Letey et al., 2000). 
Consequently, the capillary rise method, which provides direct information about water movement, is a useful alternative for characterizing the effects of hydrophobic particles in soils (Letey, 1962, Rezzoug et al., 2004, Leelamanie et al., 2008).

This article focuses on two issues: (i) a precise evaluation of the effect of the proportion of hydrophobic particles on water movement and (ii) determination of the effects of hydrophobic particles on: capillary rise, infiltration under imposed pressure, and drainage on water movement. This study used PTFE micro grains mixed with soil in order to guarantee precise proportions of hydrophobic particles. Columns of partially hydrophobic soils were used to evaluate the three flow processes; these columns were instrumented with water content sensors and an electronic scale to measure the total volume of water.

Samples with $0 \%, 2 \%$, and $5 \%$ of hydrophobic particles by weight were tested. The differences between treatment percentages were analysed by comparing the water retention curves and the dynamic of water flowing. Results show that hydrophobic particles have a huge effect on capillary rise but that water repellency decreases when pressure is imposed and that repellency becomes relevant again during drainage.

\section{MATERIALS AND METHODS}

\section{Soil type and properties}

Two materials were used to prepare the soil mixtures for this study: a fine silt and microparticles of PTFE, the hydrophobic product used in this study. Table 1 summarizes the main properties of each material. PTFE's reported contact angles are $104^{\circ}$ at $20^{\circ} \mathrm{C}$ (Omenyi, 1981) and $112^{\circ}$ at $25^{\circ} \mathrm{C}$ (Dann, 1970).

Table 1. Properties of Materials

\begin{tabular}{|c|c|c|c|}
\hline Material & Physical property & Value & Test Method \\
\hline & Bulk Density & $365-600 \mathrm{~g} / \mathrm{L}$ & ASTM D4894 \\
\hline Teflon & Average particle size $\left(D_{50}\right)$ & $3.5-4.0$ microns & Laser Light Scattering \\
\hline \multirow[t]{2}{*}{ PTFE } & Specific gravity & $2.28 \mathrm{~g} / \mathrm{cm}^{3}$ & ASTM D792 \\
\hline & Specific surface area & $2-3 \mathrm{~m}^{2} / \mathrm{g}$ & $\mathrm{N}_{2}$ Absorption \\
\hline \multirow{3}{*}{ Silt } & Average particle size $\left(\mathrm{D}_{50}\right)$ & 25 microns & ASTM D422 \\
\hline & Specific gravity & $2.69 \mathrm{~g} / \mathrm{cm}^{3}$ & ASTM D792 \\
\hline & Saturated Permeability & $2.0510^{-7} \mathrm{~m} / \mathrm{s}$ & ASTM D584 \\
\hline
\end{tabular}

Figure 1(a) shows the grain size distribution of the silt used in this study and indicates the location of size $\mathrm{D}_{50}$ of the PTFE particles which correspond to size $\mathrm{D}_{20}$ of the silt. Figure 1 (b) shows a scanning electron microscope (SEM) image of the silt, Figure 1(c) shows a SEM image of the PTFE, Figure 1(d) shows a SEM image of the $2 \%$ mixture, and Figure 1(e) shows the $5 \%$ mixture. The two last figures distinguish two types of interaction between the particles of silt and PTFE: some particles cover portions of the surface of the silt grains, and others are placed within pore spaces. 


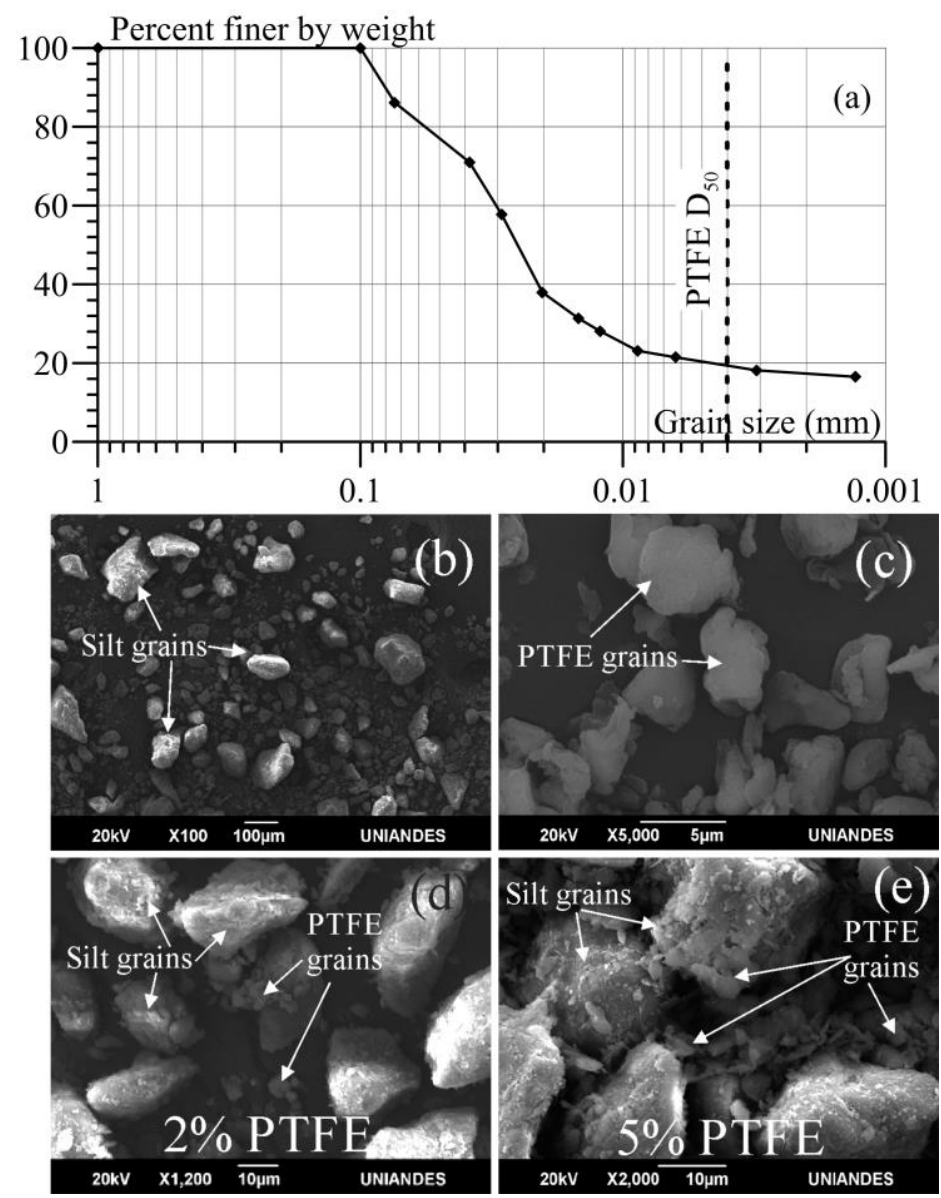

Figure 1. (a) Grain size distribution of the silt, (b) SEM image of the silt, (c) SEM image the PTFE, (d) SEM image of the mixtures at $2 \%$ (e) SEM image of the mixtures at $5 \%$.

\section{Experimental setup for flow test}

Flow tests were performed in a $0.3 \mathrm{~m}$ high soil column with a $0.1 \mathrm{~m}$ diameter as shown in Figure 2. The soil column was instrumented with five EC-5 Decagon soil moisture sensors which measure the volumetric water content based on the dielectric constant of the media. They were calibrated for the soil studied. The column has one water entrance at the base and a porous stone that distributes the water homogeneously. The water entrance is connected with a water reservoir placed over an electronic scale. Tests were performed in three stages:

(i) Capillary Rise: Water flux associated with suction and capillarity of the soil. The water level is at the lowest point of the soil sample, position A in Figure 2.

(ii) Infiltration under imposed pressure: Saturation of the material is achieved by increasing the pressure at the bottom of the column by placing the water reservoir at the top of the soil column (position B in Figure 2).

(iii)Drainage: The water reservoir is returned to its initial position at the base of the column.

Flow tests require homogeneity in both the PTFE distribution and the density of the specimen. The following procedures were used to obtain these conditions: (i) The required proportions of dry mixtures were homogenized in a rotating drum to guarantee the removal of lumps of PTFE within 
the mixture. (ii) Specimens were built in the column by placement of $20 \mathrm{~mm}$ thick layers. The bottom of the column was then vibrated to reach a constant density.

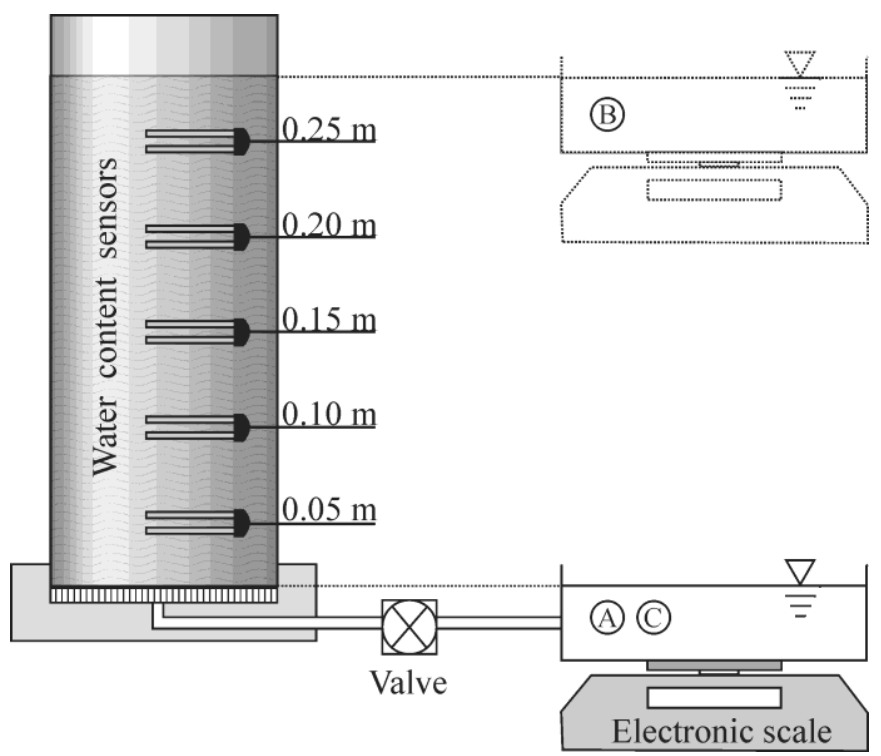

Figure 2. Schematic layout of the experimental setup for flow tests.

\section{Experimental setup for the water intrusion test}

An additional intrusion test was performed in a triaxial cell (Figure 3a.) in order to understand the interaction between PTFE and water. The procedure for assessing the repellence pressure is as follows:

(i) A sample of PTFE $50 \mathrm{~mm}$ in diameter and $50 \mathrm{~mm}$ high was placed on the base of the triaxial apparatus.

(ii) A confinement pressure of $500 \mathrm{kPa}$ was applied to densify the sample until it reached a density of $1.4 \mathrm{~g} / \mathrm{cm}^{3}$ and a porosity of $38.6 \%$.

(iii) Water was injected at the bottom of the sample by increasing the pressure. The intruded volume was then measured.

Figures $3 b$ and $3 c$ illustrate the pressure steps and the water injection volume measured on the PTFE sample. Figure 3c permits identification of two responses: a short-term intruded volume after 10 seconds of increasing pressure and a long term intrusion that continues as the rate of intruded volume decreases to stabilisation. These two responses may be due to hysteresis between dynamic and static contact angles as shown in Figure 3d. In the case of smooth PTFE, Grundke et al., 2015 found a reduction of the contact angle from $126.9^{\circ}$ in the dynamic case to $112.5^{\circ}$ in the static case. 

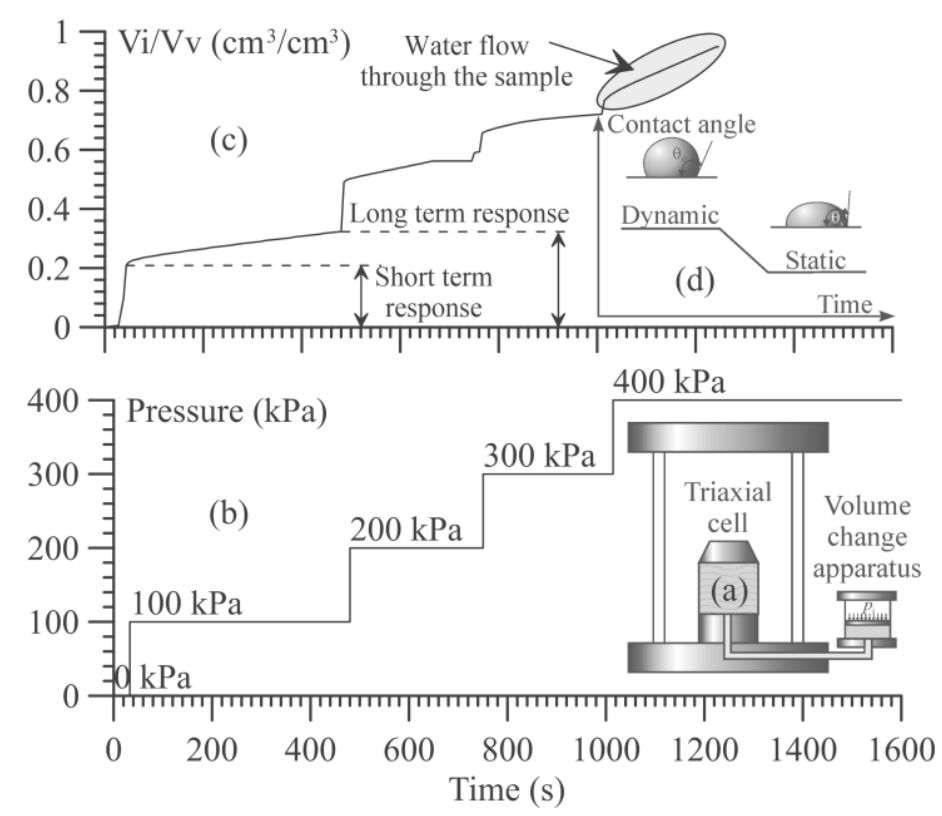

Figure 3. Water intrusion test on hydrophobic material: (a) intrusion test setup, (b) intrusion pressure steps, (c) intrusion volume (inflow) normalized by the initial void volume, (d) difference between dynamic and static contact angle (Grundke et al.,2015).

\section{EXPERIMENTAL RESULTS AND ANALYSIS}

The experimental results of this study will be presented as follows:

(i) First, the results of tests performed using the physical model for flow tests of: capillary rise, infiltration under imposed pressure, and drainage.

(ii) Second, the hydrophobic behaviour of the PTFE is presented through water repulsion curves. Then the water retention curves of the natural material and the partially hydrophobic materials are compared.

\section{Capillary Rise}

Materials with hydrophobic particles experience significant reduction of flow during capillary rise. Attenuation of the water infiltration rate and diminution of water content at saturation are the most notable differences between the natural and partially hydrophobic samples. Figure 4 exhibits the volumetric water content measured by the moisture sensors during this stage. A comparison of Figures $4 \mathrm{a}$ and $4 \mathrm{c}$ demonstrates the huge effect of the hydrophobic particles. In Figure $4 \mathrm{a}$, which shows results for natural soil, the capillary rise equilibrium was reached in 0.5 days, but for the mixture with 5\% of hydrophobic particles, equilibrium was not achieved in 50 days. 

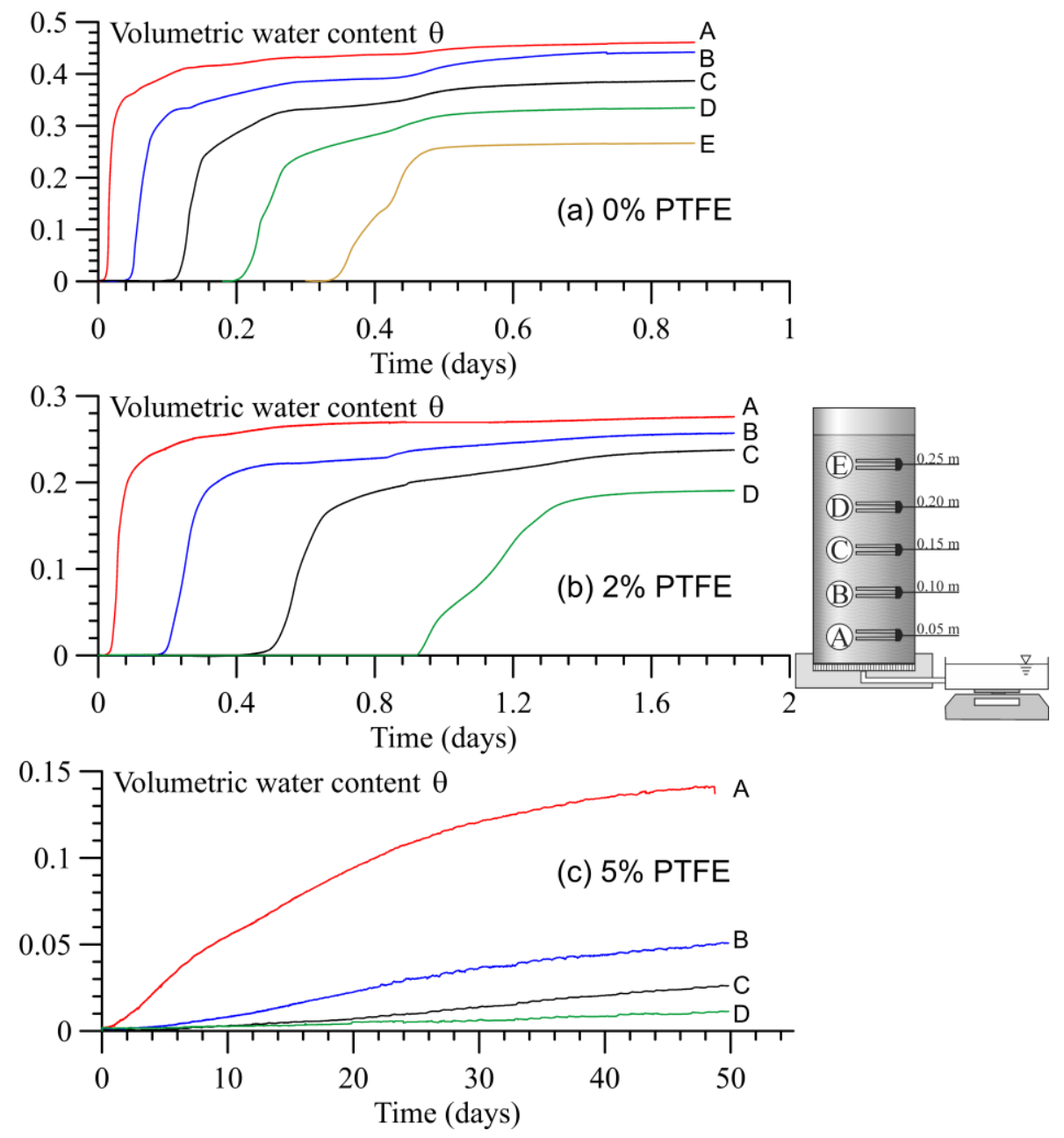

Figure 4. Results of capillary rise for 0\%, 2\% and 5\% wt. of hydrophobic particles (PTFE).

Another method for analysing capillary rise is by comparing the inflow volume as in Figure 5a. The cumulative infiltration advance through the square root of time leads to a linear trend as suggested by Laplace's equation. As shown in Figure $5 \mathrm{~b}$ and Table 2, the slope of the linear fit for the $2 \%$ PTFE mixture is 2.5 times less than the natural soil, and is 37.1 times less for the $5 \%$ mixture. This reduction in slope quantifies capillary-repulsion efficiency. 

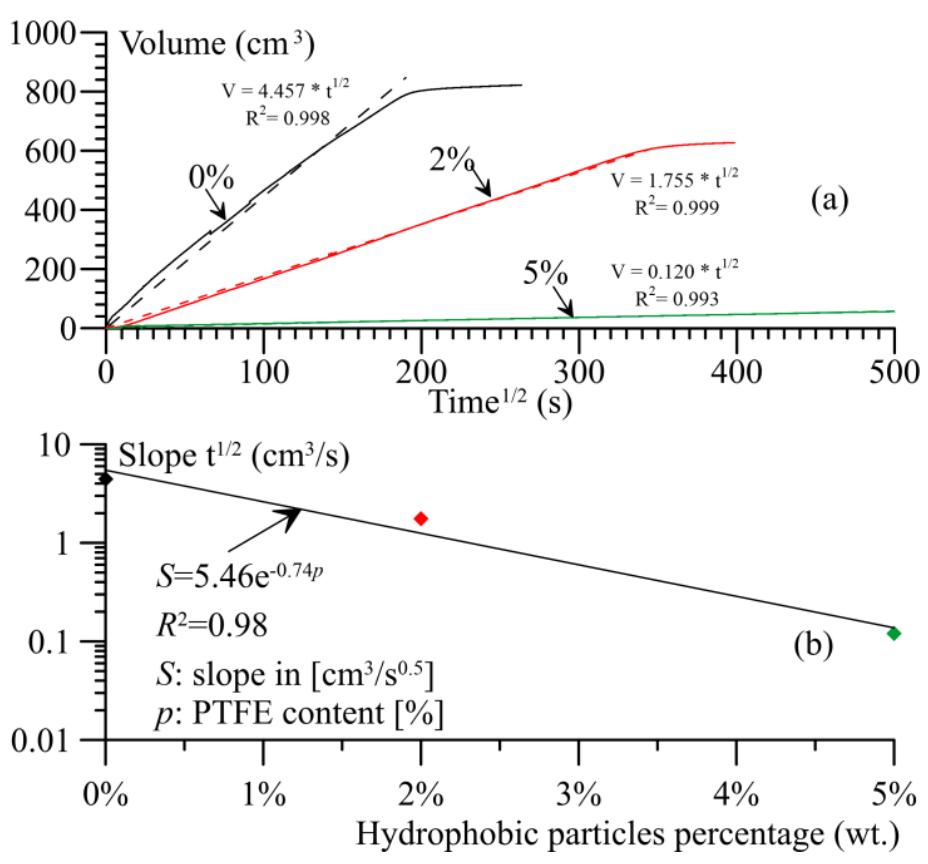

Figure 5. Capillary rise inflow of partially hydrophobic materials: (a) Cumulative infiltration in capillary rise tests, (b) capillarity-repulsion efficiency

Table 2. Capillary-repulsion efficiency of natural and partially hydrophobic materials

\begin{tabular}{ccc}
\hline Hydrophobic particle content & Slope $\mathbf{t}^{\mathbf{1 / 2}}\left[\mathbf{c m}^{\left.\mathbf{3} / \mathbf{s}^{\mathbf{0 . 5}}\right]}\right.$ & Capillary-repulsion efficiency \\
\hline $0 \%$ & 4.457 & 1 \\
$2 \%$ & 1.755 & 2.5 \\
$5 \%$ & 0.120 & 37.1 \\
\hline
\end{tabular}

\section{Infiltration under imposed pressure}

When positive water pressure is imposed at the base of the column, the repulsion effect is minimized as in Figure 6. This result appears because of reduction of the contact angle between PTFE and water. For the static case this angle fell from $112.5^{\circ}$ to close to $90^{\circ}$. Consequently, the repulsion forces became weaker and could be overcome by a small positive pressure. 

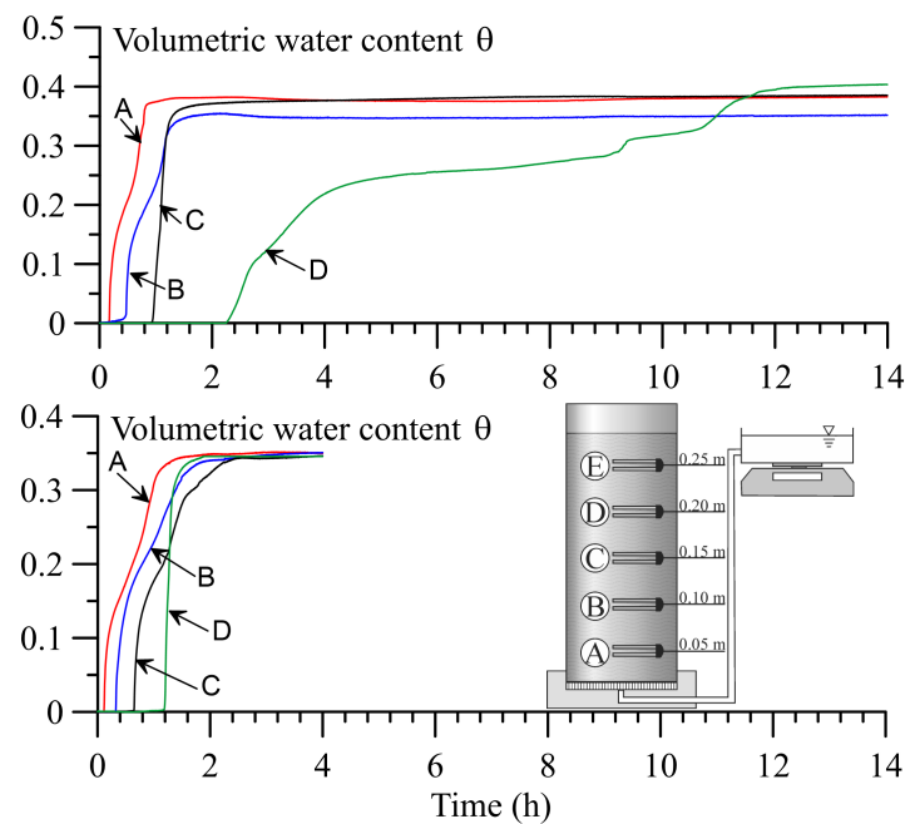

Figure 6. Infiltration under imposed pressure at the base, results for mixtures at $2 \%$ and $5 \%$ wt. of hydrophobic particles (PTFE).

\section{Drainage}

Figure 7 shows the results of the outflow volume measured for the drainage stage after saturation of the column. The water repellence of the PTFE mixtures is indicated by the drained volume of water. In fact, the drained water in the natural sample is less than $1 \mathrm{~cm}^{3}$ but increases to $80 \mathrm{~cm}^{3}$ for the mixture with $5 \%$ wt. of PTFE.

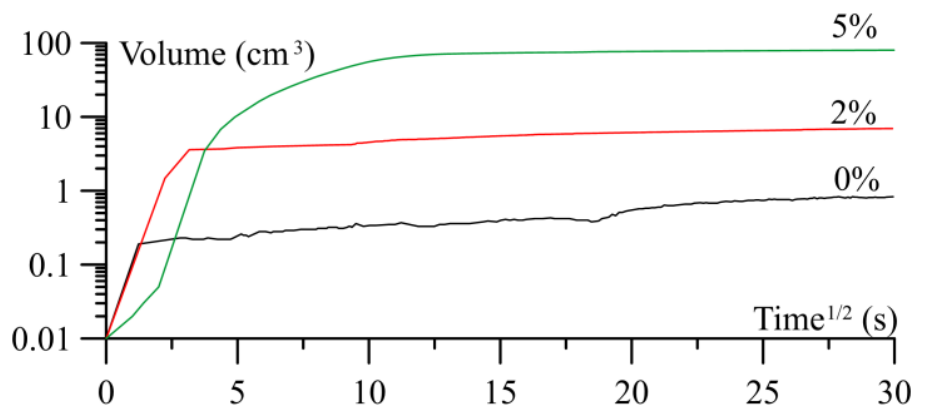

Figure 7. Outflow progress during drainage stage for mixtures at $0 \%, 2 \%$ and $5 \%$ wt of hydrophobic particles (PTFE).

\section{Water retention and repulsion curves}

The effect of hydrophobic particles (PTFE) on the water retention curves of each mixture is shown in Figures 8a to 8c. These curves were obtained using the measurements of water content at equilibrium during capillary rise and drainage. It is important to highlight that, at each suction pressure, the hydrophobic particles displace the retention curves to lower saturation values. In addition, the hydrophobic particles increase hysteresis: Natural soil's hysteresis is $0.038 \%$ while the sample with $2 \%$ hydrophobic particles increases hysteresis to $22.45 \%$, and the sample with $5 \%$ hydrophobic particles increases hysteresis to $44.83 \%$. Hysteresis was measured at $0.5 \mathrm{kPa}$ in all 
cases. Since the sample with 5\% of PTFE never reached equilibrium for capillary rise, the curve shown in Figure 8c could move to higher saturation values.

Figure 8d shows the water repulsion curve for a sample of PTFE measured during the water intrusion test. This figure permits identification of two linear trends with a breaking point at 200 $\mathrm{kPa}$. In the first section, for pressures below $200 \mathrm{kPa}$, a low level of saturation was achieved (20\%). The second section indicates that application of pressures over $200 \mathrm{kPa}$ can overcome the repellence of hydrophobic particles and easily fill voids. The incomplete stabilization at every step over 200 $\mathrm{kPa}$ suggestd that it is possible to achieve higher saturation levels under constant pressures.
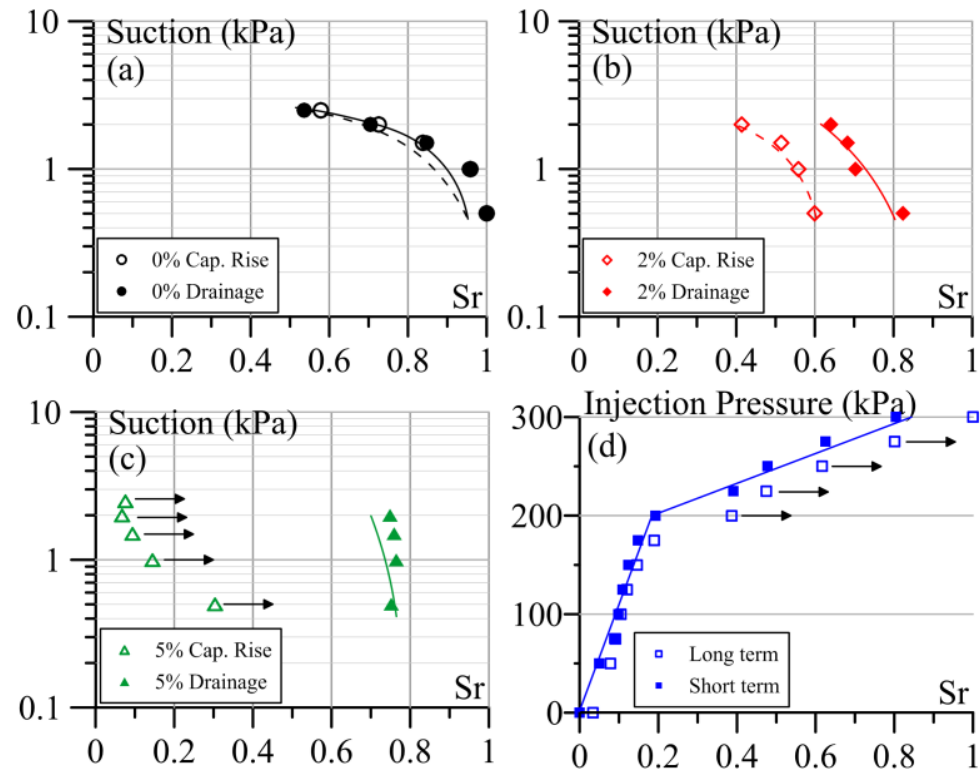

Figure 8. Water retention curves with different percentages of PTFE: (a) $0 \%$ wt., (b) $2 \%$ wt., (c) $5 \%$ wt., (d) Water repulsion curve for PTFE.

\section{CONCLUSIONS}

The purpose of this study was to procure a set of experimental results about the effects of hydrophobic particles on water movement. The presence of highly water repellent particles reduces capillary infiltration dramatically, but infiltration under imposed pressure is only slightly affected by the hydrophobic particles. Furthermore, there is greater water drainage from soil mixtures with hydrophobic particles than for natural soil. On the other hand, the characterization of PTFE resin evidences the water repulsion characteristics of this material. In addition, the comparison between mixtures exhibits significant modifications of the water retention curve. The most important conclusion of this study is that inclusion of a small amount of hydrophobic particles (in this case $5 \%$ of PTFE) dramatically modifies the soil's capillary rise but it is ineffective for reducing infiltration under positive pressure. Finally, if water saturates the soil, the hydrophobic particles can repel far more water than can natural soil.

\section{AKNOWLEDGMENTS}

Authors would like to express their gratitude to CEIBA Foundation and the Vichada Government who support the first author during her MSc studies. In addition, this publication was possible by 
the "Research Program 2012" of the Office of the Vice President for Research of the Universidad de los Andes in Bogotá, Colombia.

\section{REFERENCES}

Brandt, G. H. (1969). Water movement in hydrophobic soils. In Proceedings of symposium on water repellent soils. Riverside, California, 91-115.

Caicedo, B., Chabert, D., \& Frouin, L. (1988). Hydrophobation et imperméabilisation des sols argileux par un traitement chimique à faible dosage. Journees De Physique - Les Arcs (France), 1417 decembre 1987, 69-78.

Dann, J.R. (1970). Forces involved in the adhesive process: I. Critical surface tensions of polymeric solids as determined with polar liquids. Journal of Colloid and Interface Science, Vol. 32, 302-320.

Diamantopoulos, E., Durner, W., Reszkowska, A., \& Bachmann, J. (2013). Effect of soil water repellency on soil hydraulic properties estimated under dynamic conditions. Journal of Hydrology, 486, 175-186.

Fleureau, J. M., Wignyodarsono, L., \& Zerhouni, M. I. (1988). Effect of surfactants on the mechanical properties of a kaolinite in relation to the solid-liquid contact angles. Canadian Geotechnical Journal, 25(4), 675-683.

Grundke, K., Pöschel, K., Synytska, A., Frenzel, R., Drechsler, A., Nitschke, M. \& Welzel, P. B. (2015). Experimental studies of contact angle hysteresis phenomena on polymer surfaces - Toward the understanding and control of wettability for different applications. Advances in colloid and interface science, 222, 350-376.

Leelamanie, D. A. L., Karube, J \& Yoshida, A. (2008). Characterizing water repellency indices: Contact angle and water drop penetration time of hydrophobized sand. Soil Science and Plant Nutrition, 54:2, 179-187.

Letey, J, Osborn, J and Pelishek, R. E. (1962). The influence of the water-solid contact angle on water movement in soil, International Association of Scientific Hydrology. Bulletin, 7:3, 75-81.

Letey, J., Carrilo, M.L.K., Pang, X.P. (2000). Approaches to characterize the degree of water repellency. Journal of Hydrology 231, 61-65.

Liu, H., Z. Ju, J. Bachmann, R. Horton, and T. Ren. (2012). Moisture-Dependent Wettability of Artificial Hydrophobic Soils and Its Relevance for Soil Water Desorption Curves. Soil Science Society of America Journal, Vol 76 No. 2, 342-349

Omenyi, S. N., Neumann, A. W. and van Oss, C. J. (1981). Attraction and repulsion of solid particles by solidification fronts I. Thermodynamic effects. Journal of Applied Physics Vol. 52, 789795 .

Rezzoug, A., König, D., and Triantafyllidis, T. (2004). Scaling Laws for Centrifuge Modeling of Capillary Rise in Sandy Soils. Journal of Geotechnical and Geoenvironmental Engineering, 615620. 


\section{APPENDIX A - EC-5 MOISTURE SENSOR CALIBRATION}

EC-5 Decagon moisture sensors measure the volumetric water content of a soil by determining the dielectric constant of the media. Because this measurement depends on soil bulk density, mineralogy, texture and salinity, etc., is necessary to calibrate the sensor for the studied soil. The calibration process has been studied by the fabricant and an application note have been published, the following methodology was applied for the calibration of the five (5) sensors used in this work.

(i). Preparing several homogeneous samples of soil with variations only in the water content

(ii). Connecting the sensor to a power source at $3.0 \mathrm{~V}$. The maximum voltage specified by the fabricant for this sensors is $3.3 \mathrm{~V}$.

(iii). Introduce the sensor into the container for the sample prepared and recording the measurement.

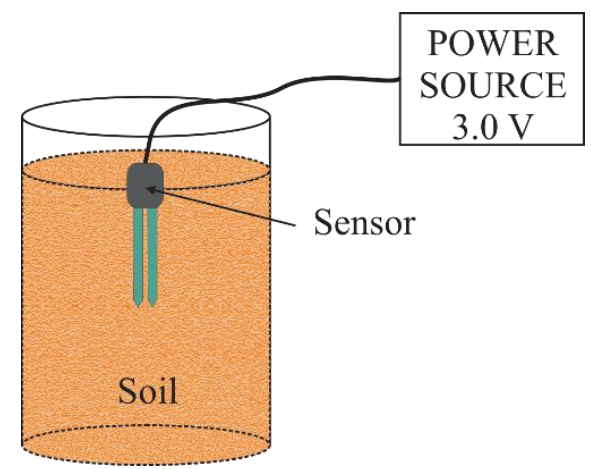

Figure A-1. Schema for EC-5 moisture sensors calibration procedure.

\section{Notes:}

- The sensor lecture is performed by introducing the sensor perpendicular to soil surface.

- Is important for the lecture that the sensor remains vertical during the sampling.

- The lecture accuracy may be compromised by the presence of empty spaces between the sensor and the soil grains. For this reason, is highly recommended not to touch or move the sample or the sensor once it is imbibed into the soil sample.

- Is recommendable to measure the water content after the sampling process in order to reduce the sample water lose.

- Different power sources give different measurements for the same sensor. For that reason, is important to perform the calibration at the same conditions that the sensors will be working.

The direct relationship between the water content and the dielectric measurement of the sensor presents a linear tendency. For that reason, after taking the measurements the data (Sensor measurement vs Moisture) is plotted and, a linear fit and calibration equation is calculated. The calibration of five sensors for natural soil sample and the corresponding equations are presented in Figure A-2. 


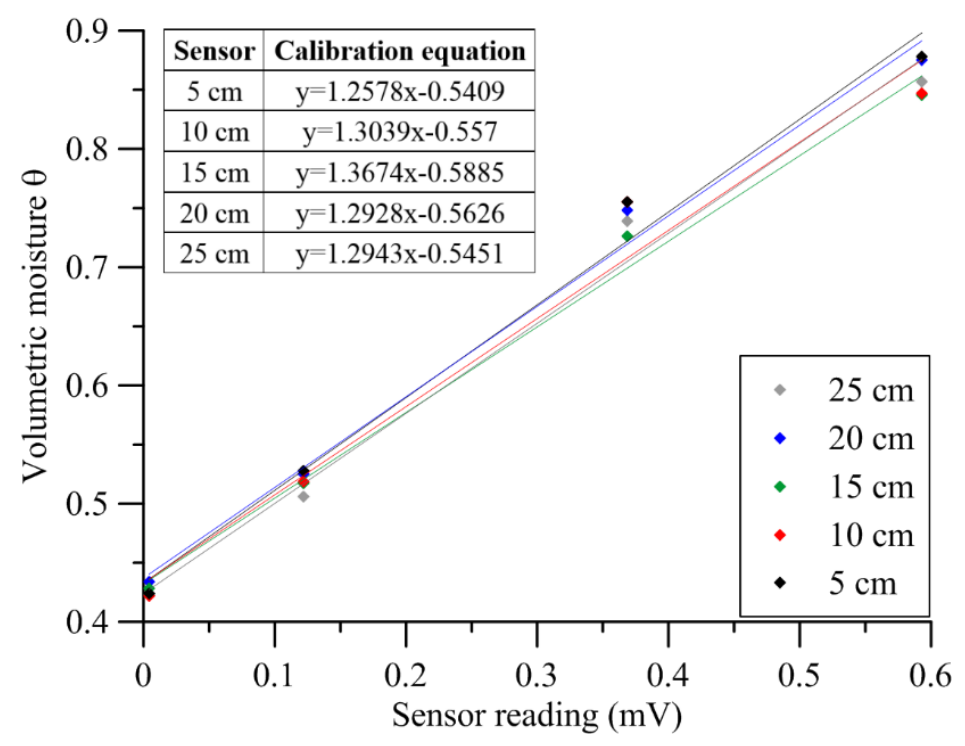

Figure A-2. Calibration data and equation for sensor studied.

\section{Interference}

To ensure accurate measurements during this study was necessary to identify the interference on sensors readings in two cases: (i) interference associated to interruption of the media (barriers), (ii) the signal interference with another EC-5 moisture sensors signals. The methodology for studying this interference consists on the comparison between sensors readings under the different conditions.

For the first case only one sensor is required. The soil was prepared in the recipient and the first measurement was done at the center of the sample. Since the recipient is circular, the distance to a wall is the radius of the recipient. After that, the sensor is moved to the wall, the distance was registered and another measurement was done. This procedure is repeated in order to test several distances between the sensor and the wall. Finally, the readings of the sensor are compared and the critical distance to wall was identified.
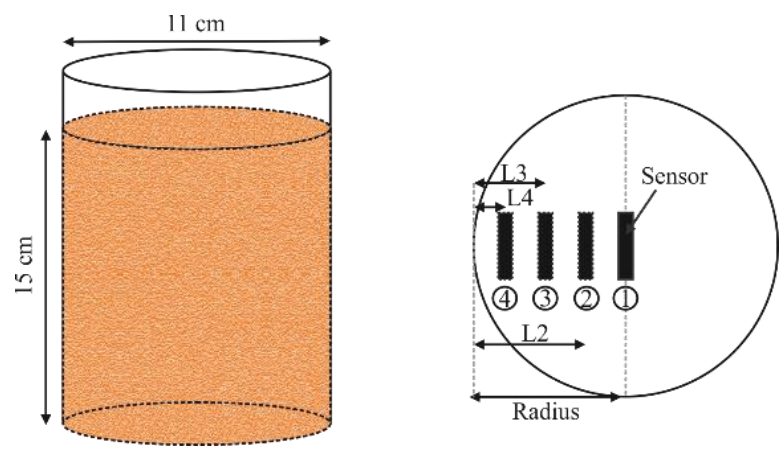

Figure A-3. Schema for interference test: case 1.

For the second case was necessary to have two sensors connected to the same power source. The soil tested is prepared on a recipient that guarantees the non-presence of barrier interference according to the first case test results. In this case, the first sensor remains at the same position during all the test and the second sensor was introduced into the sample providing a constant 
distance between both sensors. Readings before and after the presence of the second sensor in the media are recorded and compared. Finally, the differences between the sensors readings provide information about the critical separation distance. Figure A-5 shows the difference in the sensor measurements regarding the separation with the second sensor, at this is possible to split the data in two zones with its division at $5 \mathrm{~cm}$. The results of this test shows that the critical separation between sensors is between 4 and $5 \mathrm{~cm}$.
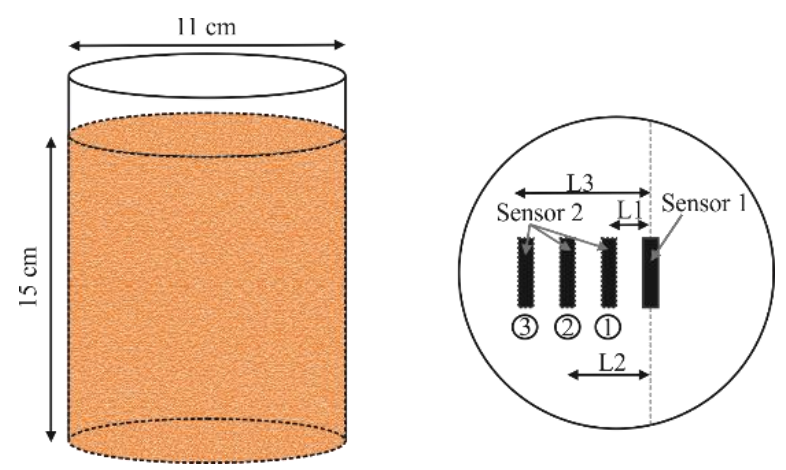

Figure A-4. Schema for interference test: case 2.

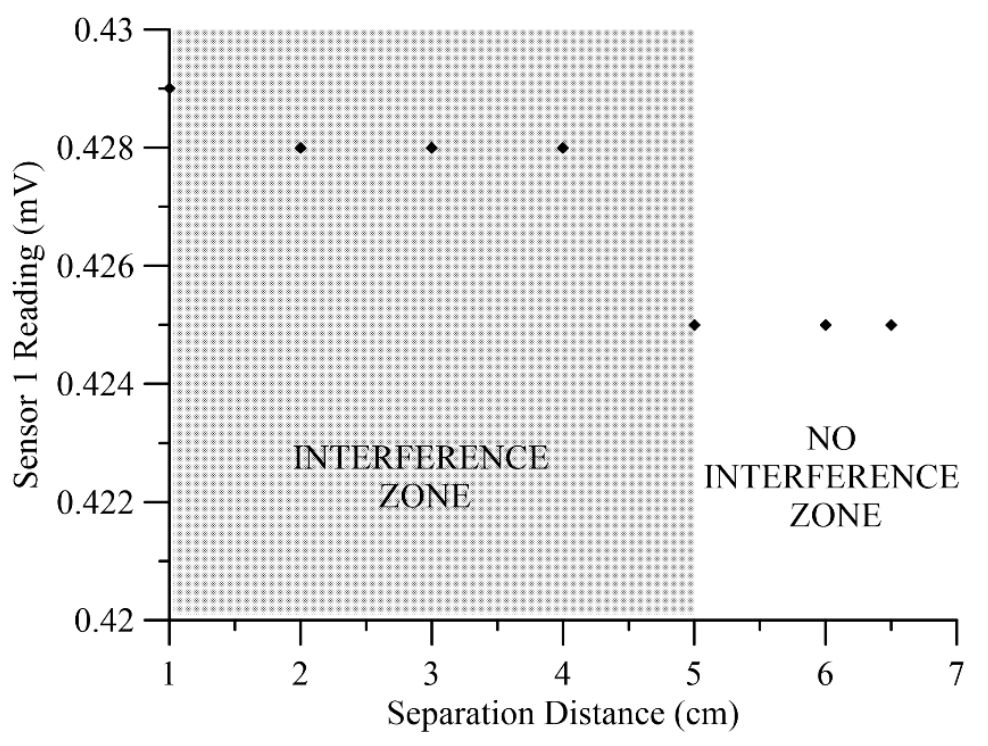

Figure A-5. Results of interference test case 2.

\section{APPENDIX B - HYPOTESIS OF PARTICLES WETTING PROCESS IN A PARTIALLY HYDROPHOBIC SOIL}

As it was mentioned before, hydrophobic particles studied through this research present a high water repellency. When a granular media that integrates both: hydrophobic and hydrophilic particles, is submitted to a wetting process is not easy to explain inter pore water flow. Since the hydrophobic particles repulse the water and contrary, hydrophilic particles will attract the water, is expected that the water flow through the pores adjacent to hydrophilic particles. This section pretends to explain the hypothesis about the water movement through the pores of a partially hydrophobic soil. 
To explain the wetting process in a soil at microscale is necessary to understand that there are many variables that take part of the process and any change on these give as consequence variations on the macroscale flow characteristics. Naturally, these characteristics are proper from each soil and depend on the saturation state. In the specific case of partially hydrophobic soils, the inclusion of water repellent particles induces changes on capillary forces, unsaturated permeability and matric suction.

One of the most important conclusions of this study was founding that the capillary rise of water became appeased when the hydrophobic particles percentage increases. Contrary, in a process of infiltration under imposed pressure the flow rate remains constant regarding the sample hydrophobic percentage. In addition, during the drainage procedure the water was expulsed due the presence of hydrophobic particles. These conclusions, indicate that in

To have a better approach to the phenomenon is useful to analyze four different cases: a complete hydrophilic soil, a sample only with hydrophobic particles, a soil with a high proportion of hydrophilic over hydrophobic particles, and a soil with a higher proportion of hydrophobic over hydrophilic particles. In a sample with only hydrophilic particles, the water fills the porous homogeneously with non-preference pattern, all the particles have the same hydraulic and wetting properties and as a result, the water infiltration only depends on suction and hydraulic potential. Opposite to that, in a sample conformed only for hydrophobic particles it is not a preferential phat that water will follows and is necessary that the water will be intruded with a pressure that overcomes the repellent forces.

The case with a higher content of hydrophilic particles is characterized by a diminution on water flow rate. This macroscale behavior may be influenced by the microscale effect associated to the presence of hydrophobic particles. Product of water repellence of these grains, water do not fill the adjacent pores. As consequence, the water only can move through the pores that connect hydrophilic particles and, as is shown in Figure B-B-1, the water do not wet the hydrophobic particles. Similarly, in the case with higher content of hydrophobic particles the water preferred to fill pores conformed by hydrophilic particles (Figure B-2). Since, in this case is more likely to found pores conformed only for hydrophobic particles, the water will be trapped in clusters of this kind of grains. The possible paths where water could move through the media are reduced to those where this condition is not present (preferential flow paths).
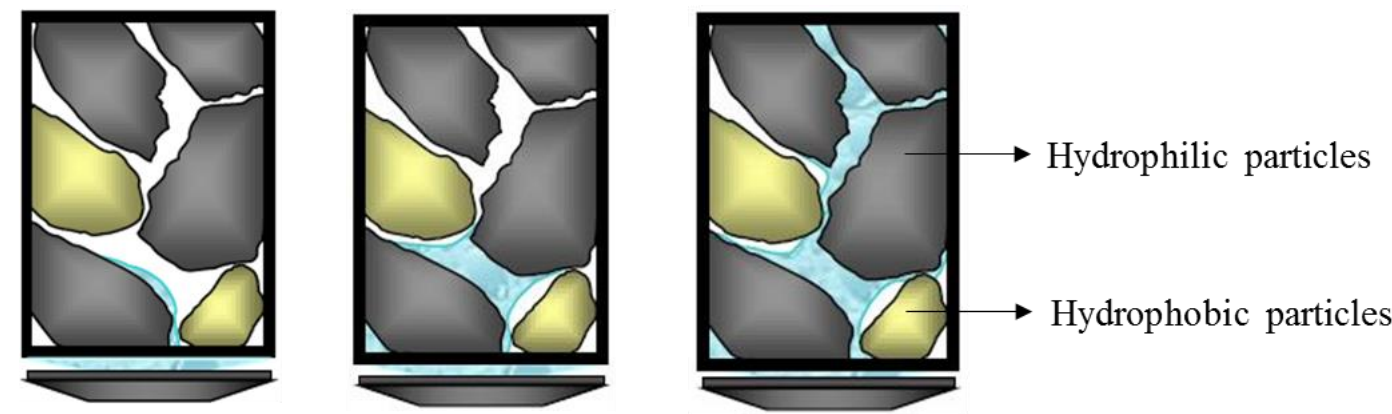

Figure B-1. Soil with a high proportion of hydrophilic over hydrophobic particles case. ${ }^{1}$

\footnotetext{
${ }^{1}$ Beatty, S. (2016) Dynamic soil water repellency in hydrological systems (Doctoral dissertation). Retrieved from McSphere: McMaster University libraries (http://hdl.handle.net/11375/19104).
} 

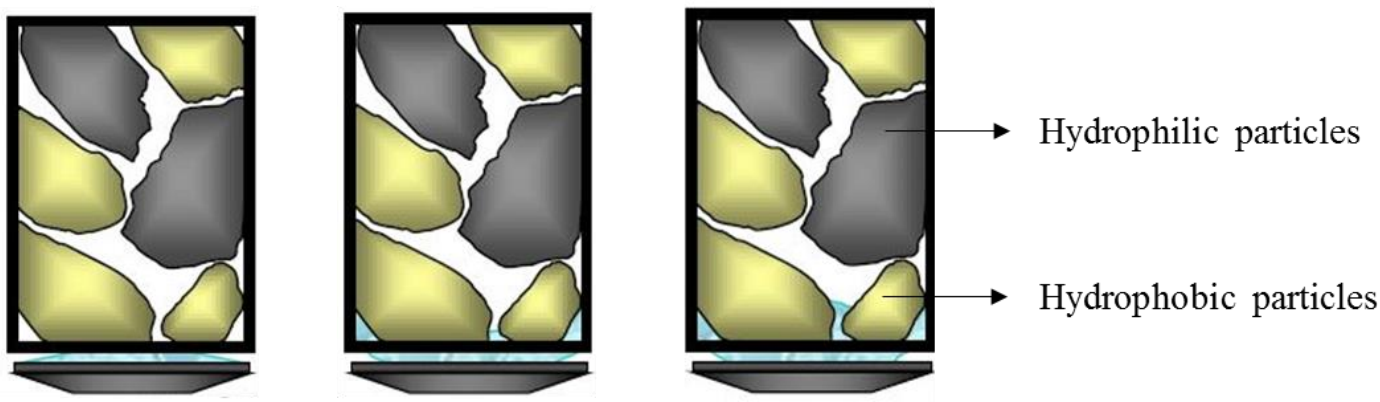

Figure B-2. Soil with a higher proportion of hydrophobic over hydrophilic particles case. ${ }^{1}$ 